\title{
West African storm tracks and their relationship to Atlantic tropical cyclones
}

Article

Published Version

Hopsch, S. B., Thorncroft, C. D., Hodges, K. and Aiyyer, A. (2007) West African storm tracks and their relationship to Atlantic tropical cyclones. Journal of Climate, 20 (11). pp. 2468-2483. ISSN 1520-0442 doi: https://doi.org/10.1175/JCLI4139.1 Available at https://centaur.reading.ac.uk/185/

It is advisable to refer to the publisher's version if you intend to cite from the work. See Guidance on citing.

Published version at: http://dx.doi.org/10.1175/JCLI4139.1

To link to this article DOI: http://dx.doi.org/10.1175/JCLI4139.1

Publisher: American Meteorological Society

All outputs in CentAUR are protected by Intellectual Property Rights law, including copyright law. Copyright and IPR is retained by the creators or other copyright holders. Terms and conditions for use of this material are defined in the End User Agreement.

\section{www.reading.ac.uk/centaur}

\section{CentAUR}

Central Archive at the University of Reading 
Reading's research outputs online 


\title{
West African Storm Tracks and Their Relationship to Atlantic Tropical Cyclones
}

\author{
Susanna B. Hopsch And Chris D. ThORnCROFT \\ Department of Earth and Atmospheric Sciences, University at Albany, State University of New York, Albany, New York \\ Kevin Hodges \\ Environmental Systems Science Centre, University of Reading, Reading, United Kingdom \\ AnANTHA AiYyer \\ Department of Earth and Atmospheric Sciences, University at Albany, State University of New York, Albany, New York
}

(Manuscript received 10 October 2005, in final form 25 September 2006)

ABSTRACT

\begin{abstract}
The automatic tracking technique used by Thorncroft and Hodges has been used to identify coherent vorticity structures at $850 \mathrm{hPa}$ over West Africa and the tropical Atlantic in the 40-yr ECMWF Re-Analysis. The presence of two dominant source regions, north and south of $15^{\circ} \mathrm{N}$ over West Africa, for storm tracks over the Atlantic was confirmed. Results show that the southern storm track provides most of the storms that reach the main development region where most tropical cyclones develop. There exists marked seasonal variability in location and intensity of the storms leaving the West African coast, which may influence the likelihood of downstream intensification and longevity.

There exists considerable year-to-year variability in the number of West African storm tracks, both in numbers over the land and continuing out over the tropical Atlantic Ocean. While the low-frequency variability is well correlated with Atlantic tropical cyclone activity, West African rainfall, and SSTs, the interannual variability is found to be uncorrelated with these. In contrast, variance of the 2-6-day-filtered meridional wind, which provides a synoptic-scale measure of African easterly wave activity, shows a significant, positive correlation with tropical cyclone activity at interannual time scales.
\end{abstract}

\section{Introduction}

The weather and climate of West Africa has a strong impact on Atlantic tropical cyclone activity. At daily time scales, most Atlantic tropical cyclones form in association with African easterly waves (AEWs) that originate over the African continent (e.g., Avila and Pasch 1992; Pasch and Avila 1994). At seasonal-todecadal time scales there is a well-known positive correlation between West African rainfall and Atlantic tropical cyclone activity (e.g., Landsea and Gray 1992). This correlation is often interpreted in terms of how anomalous large-scale latent heating over West Africa impacts the large-scale environment (e.g., vertical shear) in the so-called main development region

Corresponding author address: Susanna B. Hopsch, Department of Earth and Atmospheric Sciences, ES-351, University at Albany, State University of New York, Albany, NY 12222.

E-mail: hopsch@atmos.albany.edu
(MDR) for Atlantic tropical cyclones (e.g., Goldenberg and Shapiro 1996; Landsea et al. 1998; Thorncroft and Pytharoulis 2001; Aiyyer and Thorncroft 2006). An additional interpretation of this correlation is that variability in the AEW activity itself impacts tropical cyclone activity directly through changes in number, structure, and/or intensity. (e.g., Reed 1988; Landsea and Gray 1992; Thorncroft and Hodges 2001, hereafter TH01). Given the known importance of AEWs for downstream tropical cyclone activity on daily and possibly longer time scales, it is important to have a good knowledge and understanding of the nature and variability of AEWs as they leave the West African coast. This paper will extend the work of TH01 by including a more detailed analysis of the coherent structures associated with AEWs leaving the West African coast.

Before revisiting the work of TH01 it is important to consider what we know about AEWs and how the work of TH01 fits within this context. AEWs are usually viewed as developing via a mixed barotropic-baroclinic growth mechanism (Charney and Stern 1962) in asso-

DOI: 10.1175/JCLI4139.1 


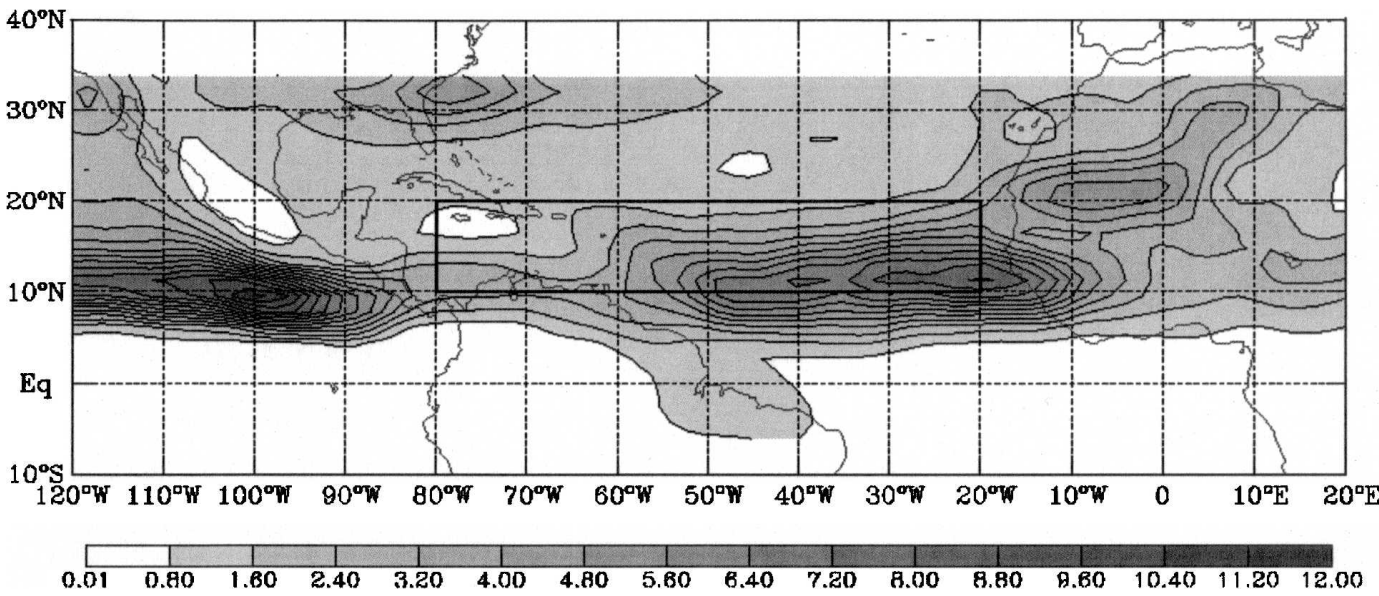

FIG. 1. Track density \{scaled to number density per unit area [with unit area equivalent to a $5^{\circ}$ radius spherical cap $\left.\left.\left(\sim 10^{6} \mathrm{~km}^{2}\right)\right]\right\}$ per month of all storm tracks over the mapped area for the months of May-November and years 1958-2002. Contour intervals (CIs) every 0.8, starting at 0.01. Also shown is the outline of the MDR and latitudelongitude lines every $10^{\circ}$.

ciation with perturbations to the meridional gradients of potential vorticity $(\mathrm{PV})$ in the region of the core of the African easterly jet (AEJ) and meridional gradients of low-level potential temperature $(\theta)$ poleward of the AEJ (Burpee 1972; Thorncroft and Hoskins 1994a; Thorncroft et al. 2003). The AEWs are synoptic-scale systems with a preferred wavelength in the 2000-4000$\mathrm{km}$ range, as highlighted in composite studies and Hovmöller analysis of AEWs (e.g., Reed et al. 1977; Diedhiou et al. 1999; Kiladis et al. 2006). AEWs also possess subsynoptic-scale ${ }^{1}$ structures that are associated with nonlinear developments (e.g., Thorncroft and Hoskins 1994b), PV anomalies generated by convection in mesoscale convective systems (MCSs; e.g., Schubert et al. 1991), or a combination of these. In a recent case study of an intense AEW that occurred in the summer of 2000, Berry and Thorncroft (2005) highlighted the importance of the merger of such subsynoptic PV anomalies in the vicinity of the Guinea Highlands near the West African coast and suggested that the resulting coherent structure was important for providing a favorable trigger for Hurricane Alberto. Alberto was named $18 \mathrm{~h}$ after the coherent structure left the West African coast. It is likely that the coherent vorticity structures tracked by TH01 in the Guinea Highlands region formed through similar processes and represent a particular aspect of AEWs that may be important for downstream tropical cyclones. We also recognize how-

\footnotetext{
${ }^{1}$ By subsynoptic we mean smaller than the wavelength of an AEW; here we are referring to coherent vorticity structures embedded within AEWs.
}

ever that other mechanisms may also be operating to encourage tropical cyclogenesis just downstream of West Africa. A detailed analysis of the relative roles of the weather systems versus large-scale environment (e.g., sea surface temperatures, vertical shear, and large-scale convergence; cf. Webster and Chang 1988) is needed but will not be addressed here.

TH01 presented an analysis of the coherent vorticity structures associated with AEWs over West Africa and the tropical Atlantic based on data that included the 15-yr European Centre for Medium-Range Weather Forecasts (ECMWF) Re-Analysis (ERA-15; Gibson et al. 1997) extended with $5 \mathrm{yr}$ of operational analysis. Consistent with other studies (e.g., Reed et al. 1988; Lau and Lau 1990), their study indicated the existence of two dominant storm tracks. One was found south of about $15^{\circ} \mathrm{N}$ in the rainy zone, with a track density maximum just offshore of the West African coast and a clear extension across the Atlantic. A second, which has a very weak connection to the Atlantic, was located north of $15^{\circ} \mathrm{N}$ on the fringes of the Sahara. Figure 1 shows the mean May-November 1958-2002 850-hPa track density based on the 45-yr ECMWF Re-Analysis (ERA-40; see section 2 for details). Consistent with the findings of TH01 and their Fig. 6a, it is clear that these two tracks provide the majority of storms that track from Africa into the tropical Atlantic. They suggested that the systems provided by the southern storm track continue downstream along the oceanic storm track, whereas features coming off the West African Coast from the northern storm track rarely propagate far out over the tropical Atlantic Ocean. TH01 showed that the southern storm track exhibits marked interannual variability 
and suggested that this variability may have some association with tropical cyclone activity. For the second half of their time series (years 1985-98) the numbers of coherent vortices and named Atlantic tropical cyclones appeared to change in concert. However, firm conclusions could not be made based on this analysis as a result of the short period of $20 \mathrm{yr}$.

The present study extends TH01's analysis by considering the relationship between the storm tracks over West Africa and the tropical Atlantic in more detail and for $45 \mathrm{yr}$. We will continue to focus on $850-\mathrm{hPa}$ vorticity-as we know that low-level vorticity is important for tropical cyclogenesis (e.g., Gray 1968). Specifically, the nature of the climatology and variability are examined from a vorticity tracking perspective. Throughout the text, we will refer to these structures as storm tracks, and reserve the terms tropical storms and tropical cyclones entirely to named storms from the best-track dataset. A major aim of this work is to provide an analysis of the storms that leave West Africa, including an assessment of the relative roles of the northern and southern storm tracks, their variability, and relationship with tropical cyclones.

While little is known about the nature and variability of the coherent structures that were the focus of TH01 as well as of most of this present study, relatively more is known about synoptic measures of AEW variability. This is usually approached by considering the variance associated with time-filtered meridional wind or outgoing longwave radiation (OLR; e.g., Reed 1988; Grist and Nicholson 2001; Mekonnen et al. 2006; Berry et al. 2007). Such measures clearly smooth out the coherent structures, thus obscuring their relationships with the AEWs. Previous studies cited above have shown that the synoptic AEW variability does indeed exhibit marked interannual variability, which tends to be positively correlated with West African rainfall. The relationship of synoptic AEW variability with tropical cyclone variability has not previously been considered and so for completeness, we will briefly consider this relationship for comparison with the variability of the coherent structures.

The organization of this paper is as follows. A description of the data and methodology used is given in section 2. A climatological perspective of the storm tracks and comparison with tropical cyclone activity is provided in section 3 . In section 4 we discuss the variability of the storm tracks including an investigation of their relationship with tropical cyclone variability. This is followed by a discussion section that includes a comparison with the synoptic-scale variability. The paper is concluded with a summary and final comments section.

\section{Data and methodology}

In this analysis, data from the reanalysis project, ERA-40, from ECMWF is used (Uppala et al. 2005). This dataset covers the period 1958-2002, and has been produced using the Integrated Forecast System to assimilate the wide range of inhomogeneous observations with a full general circulation model. ERA-40 uses a spectral model with a spectral resolution of triangular truncation 159 (T159, nominally $320 \times 160$ grid points) in the horizontal and with 60 vertical levels; it utilizes a three-dimensional variational data assimilation scheme and has fully parameterized physics packages. Details can be obtained from the ECMWF Re-Analysis project Web site (http://www.ecmwf.int/research/era/). It is appropriate to use some caution when using reanalysis data for the presatellite era (i.e., 1958-78), since due to the limited amount of observations through the Tropics, the dataset relies more heavily on the model than observations.

Three other datasets that were used in this study are the Mike Hulme precipitation dataset from 1958 to 1998 with a grid resolution of $2.5^{\circ}$ latitude $\times 3.75^{\circ}$ longitude (Hulme 1992), the Hadley Centre's sea surface temperatures (SSTs) from 1958 to 2002, with a grid resolution of $1^{\circ}$ latitude $\times 1^{\circ}$ longitude (Rayner et al. 2003), and the National Hurricane Center's (NHC's) best-track dataset, which is prepared postseason using all available observations (ships, land stations, buoys, research and reconnaissance aircraft, radar, and satellites). These datasets are primarily used to support the analysis of variability in section 4 .

The method for storm tracking and generation of storm-track statistics follows the approach by TH01. As in their study, the tracking of the 6-hourly vorticity centers was performed on a spectral resolution of T42 (nominally $128 \times 64$ grid points), as this has shown to yield less noisy results, while capturing the storm systems sufficiently well. In this study, the positive vorticity anomalies need to fulfill certain criteria with respect to intensity (closed vorticity contours with values of at least $+0.5 \times 10^{-5} \mathrm{~s}^{-1}$, longevity (minimum lifetime of 2 days), and propagation [minimum of at least $10^{\circ}$ $(\sim 1000 \mathrm{~km})]$ to be considered as a valid track (see TH01; Hodges 1995, 1996 for details). The track data were then processed to generate storm-track statistics, an example of which is shown in Fig. 1. Special attention was given to the track data for the $850-\mathrm{hPa}$ level from July through October, the height of the Atlantic tropical cyclone season.

\section{Storm-track statistics: Climatology}

The track density shown in Fig. 1 indicates a coherent storm track in the tropical Atlantic. This oceanic storm 
track coincides in large part with the location of the MDR (as defined by Goldenberg and Shapiro 1996), stretching from $10^{\circ}$ to $20^{\circ} \mathrm{N}$ and $20^{\circ}$ to $80^{\circ} \mathrm{W}$. As mentioned in the introduction, most tropical storms in the Atlantic form within or in close proximity of the MDR (cf. Fig. 1 of Emanuel 2003). Interestingly, the peak track density axis is located in the southern half of the MDR, with highest activity in the southeast corner just downstream of the Guinea Highlands, a prominent genesis region for storms identified by TH01. The track density noticeably weakens downstream of this region, consistent with a generally unfavorable environment for maintenance or intensification of these storms (e.g., due to cool SSTs, close proximity to dry air, vertical shear, or dispersion on a single-signed PV gradient).

Since a major objective of our work is to investigate the nature of the storms that may influence tropical cyclogenesis, we focus only on those that at some point in their life cycle existed in the eastern half of the MDR over the tropical Atlantic, that is, within a region from $10^{\circ}$ to $20^{\circ} \mathrm{N}$ and $20^{\circ}$ to $50^{\circ} \mathrm{W}$. Through the use of this "filter" we will obtain an objective view of the potentially important storms for tropical cyclogenesis and an objective assessment of the different roles of the northern and southern storm tracks over Africa.

\section{a. Seasonal mean}

Figure 2 shows maps of track density and genesis density for all tracks found in the eastern half of the MDR, for the entire time series from 1958 to 2002, and for May through November. The highest track density is found along a relatively narrow strip over the ocean between $11^{\circ}$ and $15^{\circ} \mathrm{N}$ and from $20^{\circ}$ to $35^{\circ} \mathrm{W}$. The eastward extension of the major track density axis approaches $10^{\circ} \mathrm{N}$ and can be traced to about $5^{\circ} \mathrm{W}$ over the land. Only a few MDR tracks have their origin east of $5^{\circ} \mathrm{W}$. The northern track does not appear to significantly contribute to the downstream storm track. The westward extension of the track density over the ocean shows a gradual weakening for reasons already discussed above. The storm track axis is oriented zonally to around $50^{\circ} \mathrm{W}$, with an indication of a slight poleward orientation at the end consistent with the preferred track of tropical cyclones and weaker systems around the subtropical high.

Figure $2 b$, the genesis density map, shows two distinct genesis areas for systems found inside the eastern MDR. The most prominent region is centered over northwest Guinea (Moyenne-Guinée and the Guinea Highlands) around $10^{\circ} \mathrm{N}, 12^{\circ} \mathrm{W}$. This genesis region is rather broad and is shown to span almost $15^{\circ}$ longitude (from $10^{\circ}$ to $25^{\circ} \mathrm{W}$ ) and approximately $8^{\circ}$ latitude (from $8^{\circ}$ to $\left.16^{\circ} \mathrm{N}\right)$. TH01 argued that this region is associated with latent heat release from deep moist convection in the vicinity of the Guinea Highlands. It also corresponds to the region of PV merger and spinup noted in the AEW case study of Berry and Thorncroft (2005). Note that very few storm tracks originate in the heat low region to the north, and these tracks appear not to contribute significantly to the storm-track activity in the MDR. It suggests that the primary genesis area for African precursors is likely associated with moist convection over the Guinea Highlands (TH01) and occasional PV mergers (Berry and Thorncroft 2005).

It should also be noted that not all storms tracked in the eastern MDR are generated over the continent. A second peak in genesis density is located around $\left(12^{\circ} \mathrm{N}\right.$, $\left.38^{\circ} \mathrm{W}\right)$. Although this is a weaker peak than that associated with the Guinea Highlands, it does suggest that coherent structures can also develop over the ocean, presumably in association with convection and the passage of synoptic AEWs (see section 5). This region of peak genesis has also been seen in studies of tropical cyclogenesis (e.g., Frank 1975, his Fig. 1; Simpson et al. 1969), indicating that the oceanic genesis seen in the ERA-40 analyses also includes tropical cyclogenesis events. A closer look at different roles played by synoptic AEWs and the environmental conditions is required to shed light on the reasons for this secondary peak in genesis and will be the subject of future work.

The total number of storms coming off the West African Coast according to their respective latitude is shown in Fig. 3 along with the overall number of systems that propagate into the MDR. This confirms the presence of two dominant storm tracks over West Africa with a very strong contribution from latitude segments from $10^{\circ}$ to $15^{\circ} \mathrm{N}$ (the southern storm track), and a weaker contribution from $20^{\circ}$ to $22^{\circ} \mathrm{N}$ (the northern storm track). Approximately $75 \%$ of the southern storm tracks continue to the MDR compared with only about $20 \%$ of the northern storm tracks. This confirms the perception of TH01 that the southern, moist storm track is the main track to consider for downstream tropical cyclogenesis. It also highlights the importance of paying close attention to the Guinea Highlands as a genesis region for these storm tracks, a region that presently has very few in situ observations.

\section{b. Seasonal cycle}

Given the known seasonality in West African rainfall and tropical cyclone activity, it is important to consider how these storm-track statistics vary during the Northern Hemisphere summer. Figure 4 shows the track density and genesis density for the storm tracks found within the eastern MDR for June through October (the "filtered" tracks). 


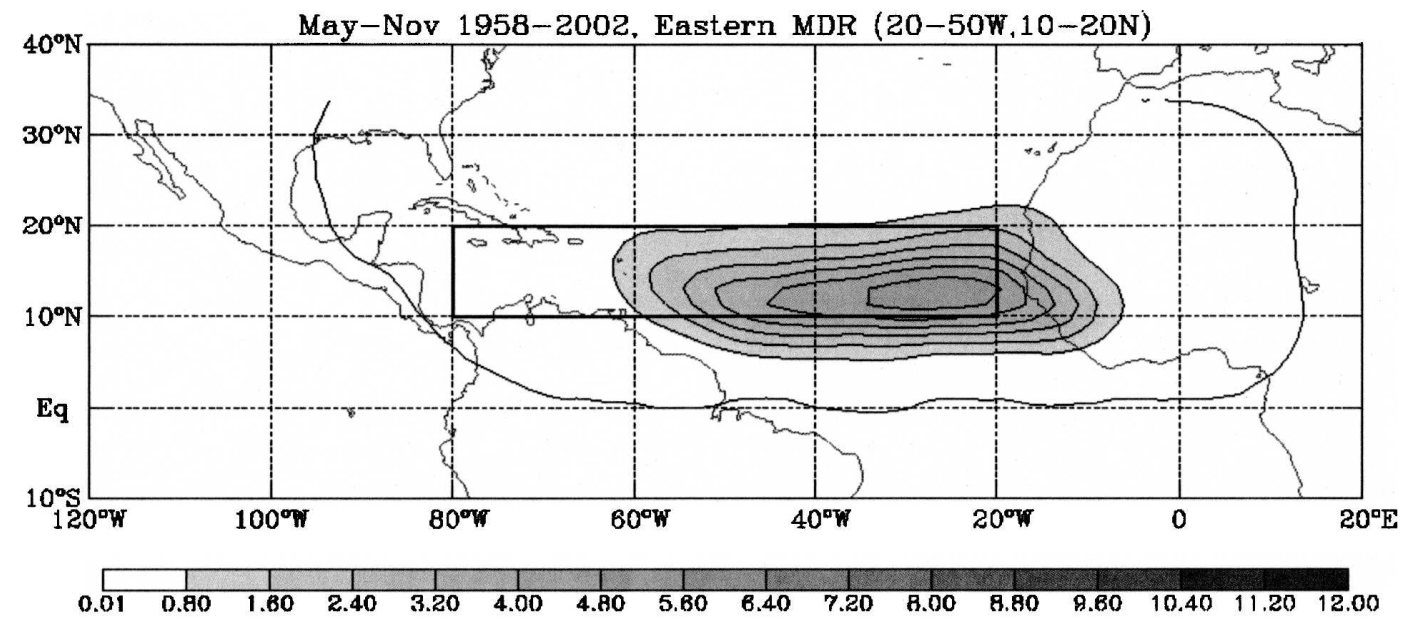

a) Track density

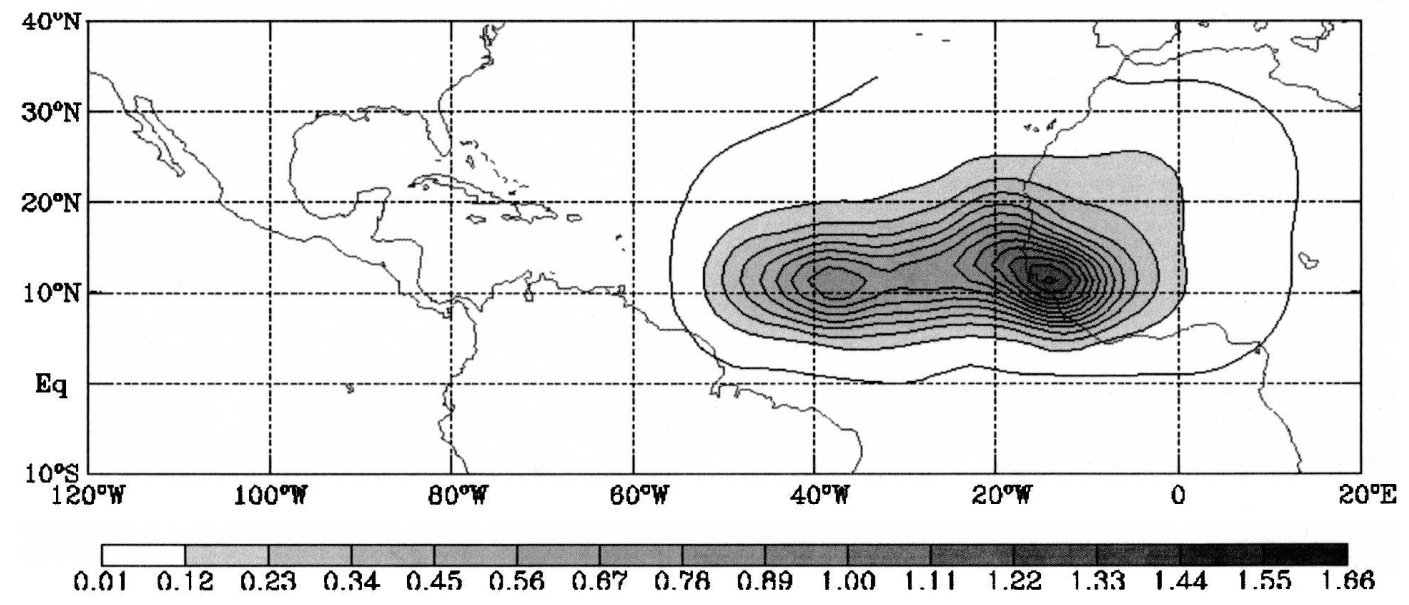

\section{b) Genesis density}

FIG. 2. (a) Track density (scaled to number density per unit area [with unit area equivalent to a $5^{\circ}$ radius spherical cap $\left(\sim 10^{6} \mathrm{~km}^{2}\right)$ ] per month\}, with contours every 0.8 , starting at 0.01 . Also shown is the outline of the MDR and latitude-longitude lines every $10^{\circ}$. (b) Genesis density \{scaled to number density per unit area [with unit area equivalent to a $5^{\circ}$ radius spherical cap $\left.\left.\left(\sim 10^{6} \mathrm{~km}^{2}\right) \mathrm{month}^{-1}\right]\right\}$, with contours every 0.11 starting from 0.01 . The statistics maps are produced using all tracks from May through November, 1958-2002, that pass through the eastern half of the MDR $\left(10^{\circ}-20^{\circ} \mathrm{N}, 20^{\circ}-50^{\circ} \mathrm{W}\right)$.

The track density is characterized by a broad, elongated region of peak activity over the eastern Atlantic Ocean during all months, consistent with the seasonal mean discussed above. The activity increases from June through September, when the track density peaks, and then decreases into October. The track density axis in June is aligned zonally around $12^{\circ} \mathrm{N}$ and extends from around $10^{\circ} \mathrm{W}$ to around $55^{\circ} \mathrm{W}$. Between June and July the track density increases slightly, shifts poleward by a few degrees, and also indicates more recurving storms in the western Atlantic. What is also striking in July is an indication of an increased importance of the north- ern track compared to that in June. This track density pattern is even more enhanced in August. It should be noted, however, that the northern tracks, as could be deduced from the previous figures, very rarely enter the MDR. The absolute peak in track density for storm tracks in the eastern MDR is found to occur in September, which is the month when tracks propagating through the eastern half of the MDR can occasionally be tracked as far west as the Caribbean and Puerto Rico. The track densities also show the clearest recurving pattern toward the northwest. In September there is no evidence for the northern track providing storms in 


\section{\# tracks passing 10 - 20W longitude strip 1958 - 2002}

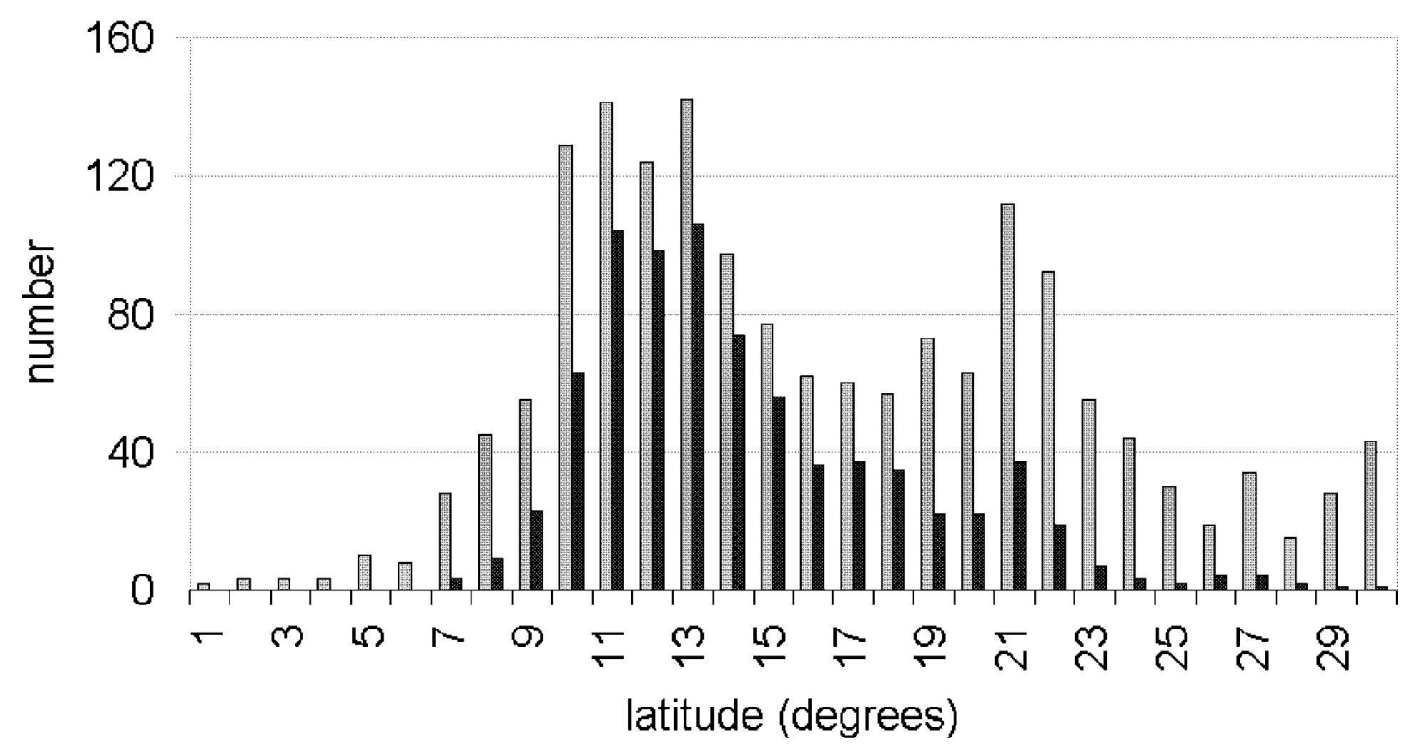

total $\mathbf{m}$ to MDR

FIG. 3. Number of storm tracks during May-November, from 1958 to 2002, found within longitude of $10^{\circ}$ to $20^{\circ} \mathrm{W}$ and number of storm tracks that further continue to the MDR (light and dark gray, respectively) vs latitude.

the MDR. By October, the track density has decreased in magnitude and shows a weaker recurving signal and no evidence for a role played by the northern track.

The primary genesis peak seen in the seasonal mean can also be seen in the monthly means, but there are some notable shifts in position and changes in intensity. The intensity of the genesis density peak is highest in September and October when it is clearly linked to the convectively active Guinean Highlands. The genesis density is less intense in July and August, and the location of the maxima shifted slightly over the ocean around $15^{\circ}-16^{\circ} \mathrm{N}$, slightly poleward of the Guinea Highlands. The secondary genesis maximum over the ocean is seen most prominently in August, but weak genesis is seen in the mid-Atlantic in all months.

\section{c. Storm characteristics}

The analysis presented above highlights the strong contribution of coherent vorticity structures that develop over the Guinea Highlands for the storm track in the eastern MDR, especially in September and October. We will now look more closely at the fate of these systems by examining the lifetime of the systems leaving Africa and examine if storm amplitudes over Africa are related to their downstream intensity.
Figure 5 shows the lifetime in days for all storms that were found in a $10^{\circ} \times 10^{\circ}$ box (starting from the time the storms leave the box), centered on the primary peak genesis areas shown in Fig. 4. In June and July (Figs. $5 a, b)$, most storms had a lifetime of 3-5 days, with a slight indication of longer lifetimes in July. It also indicates that most of these storms dissipate somewhere over the midocean or eastern parts of the tropical North Atlantic. As the season progresses, there are more long-lived storms, with a marked increase in the number of systems that prevail for more than one or two weeks (also the number of short-lived systems decreases), as seen in Figs. 5c,d. During October (Fig. 5e), there are fewer long-lived storms.

Figure 6 shows scatterplots to highlight the systems' intensities in terms of the magnitude of the vorticity for the identified track for June through October. The intensity of each system as it comes off the West African coast around $20^{\circ} \mathrm{W}$ (i.e., the intensity of the westernmost point between $10^{\circ}$ and $20^{\circ} \mathrm{W}$ ) is plotted against the maximum intensity of the same system downstream over the ocean. If a tracked feature does not intensify, or if the system does not proceed over the Atlantic Ocean, then the maximum intensity is kept at the same value it had at the West African coast. In June (Fig. 6a), 
Track density
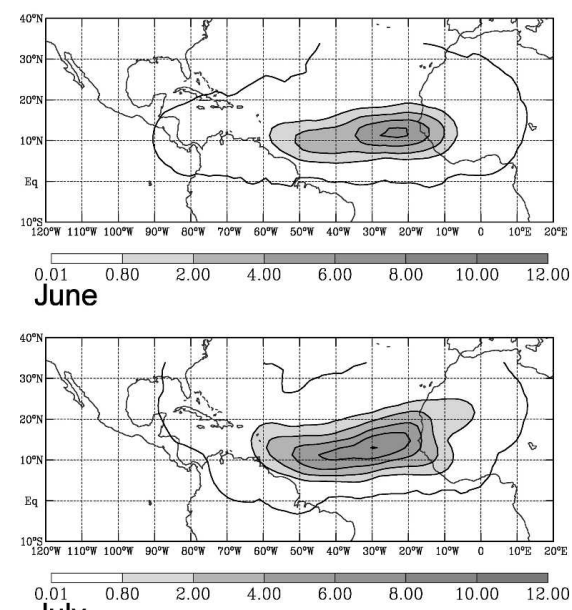

july
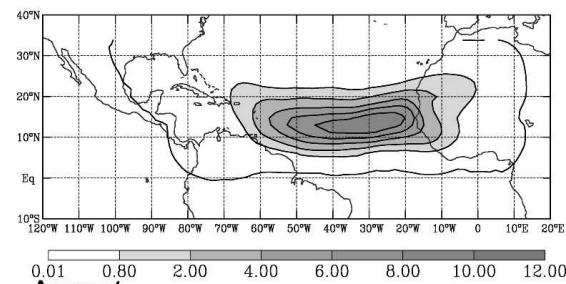

August
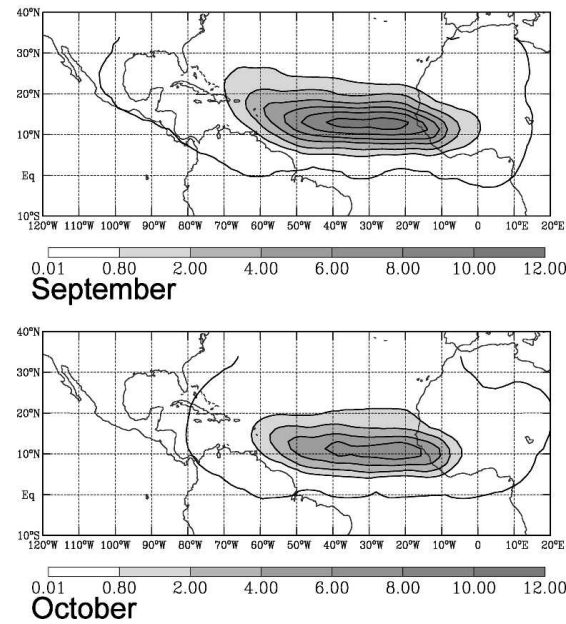

Genesis density
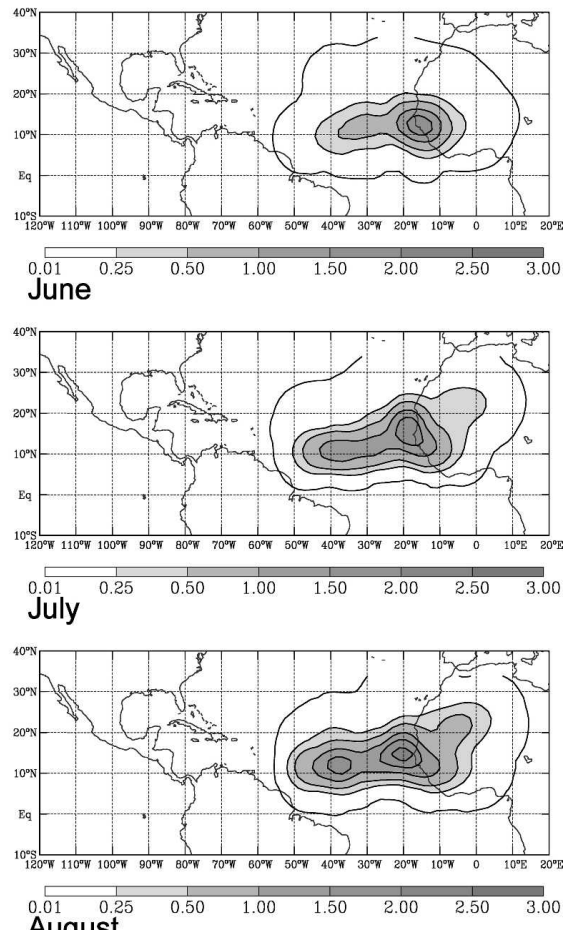

\section{August}
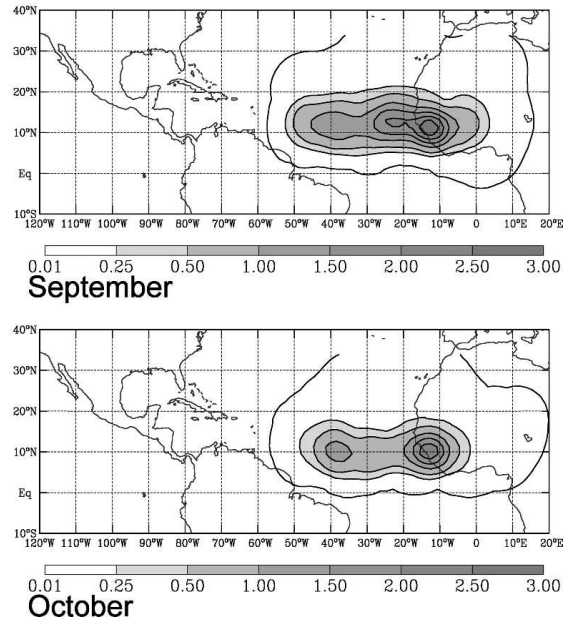

FIG. 4. Track density and genesis density \{scaled to number density per unit area [with unit area equivalent to a $5^{\circ}$ radius spherical cap $\left.\left(\sim 10^{6} \mathrm{~km}^{2}\right)\right]$ per month\}, shown for the months of June-October, from top to bottom. The statistics maps are produced using all tracks (1958$2002)$ that pass through the eastern half of the MDR $\left(10^{\circ}-20^{\circ} \mathrm{N}, 20^{\circ}-50^{\circ} \mathrm{W}\right)$. Latitudes and longitudes are shown for every $10^{\circ}$.

the systems coming off the West African coast only have a moderate intensity (of the order of $2-4 \times 10^{-5}$ $\mathrm{s}^{-1}$ ) and show limited further intensification. In July (Fig. 6b), the range of intensities increases slightly (now systems from $2-8 \times 10^{-5} \mathrm{~s}^{-1}$ can be found, except for one outlier near $1 \times 10^{-4} \mathrm{~s}^{-1}$ ), but still no features are noted whose relative intensity increases markedly (i.e., doubling its magnitude) over the ocean. This situation changes for August and September, where both the number of intense systems is increased and several systems now show marked intensification over the Atlantic Ocean. This seasonal cycle of increased activity and intensification during August and September is in concert with an increase in the lifetime (noted before), and 
a) 1958-2002 lifetime, Jun

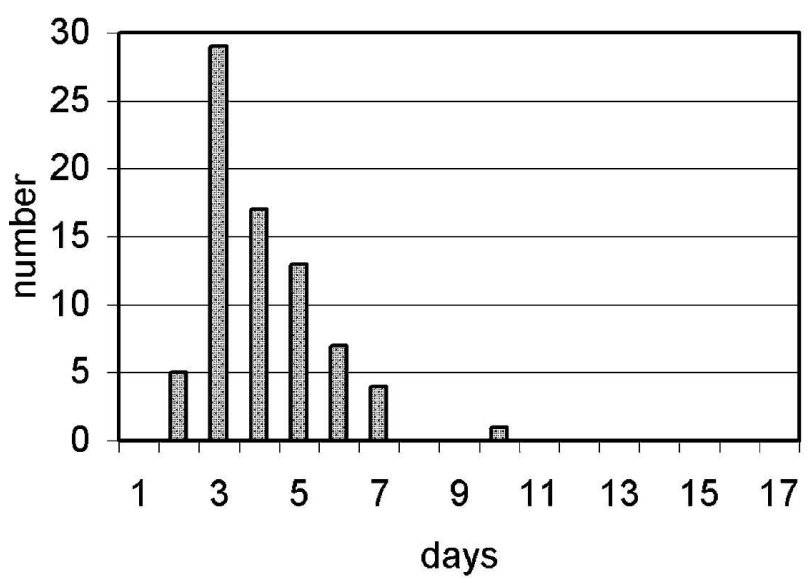

c) 1958-2002 lifetime, Aug

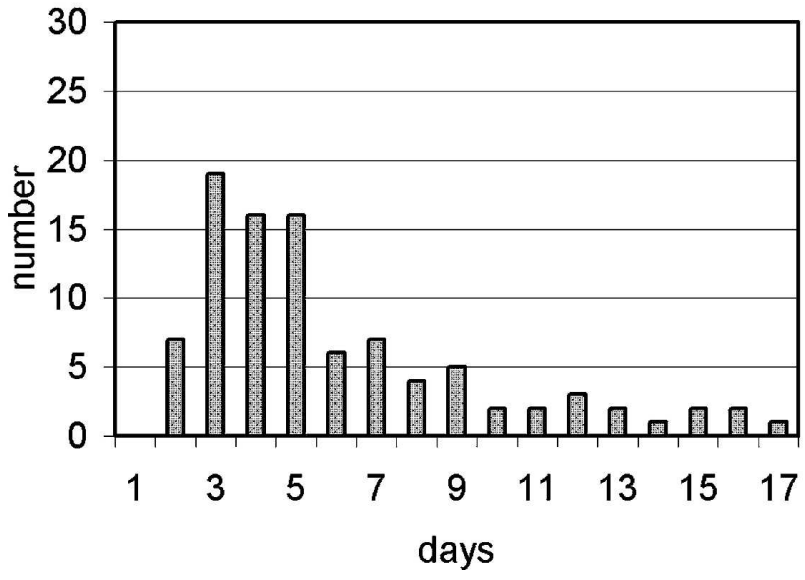

e) 1958-2002 lifetime, Oct

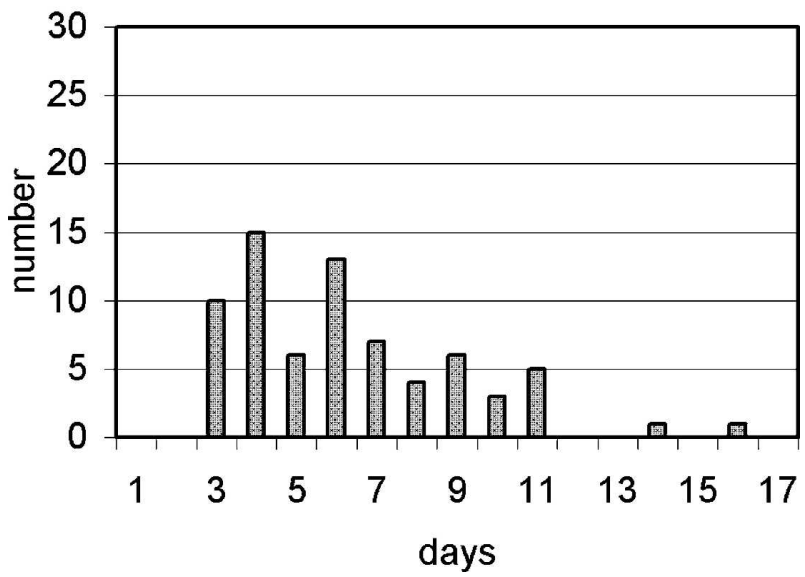

distance traveled (not shown). The data strongly suggest that the amplitude of the storms leaving the West African coast may be a contributing factor to downstream intensification, particularly in August and Sep- b) 1958-2002 lifetime, Jul

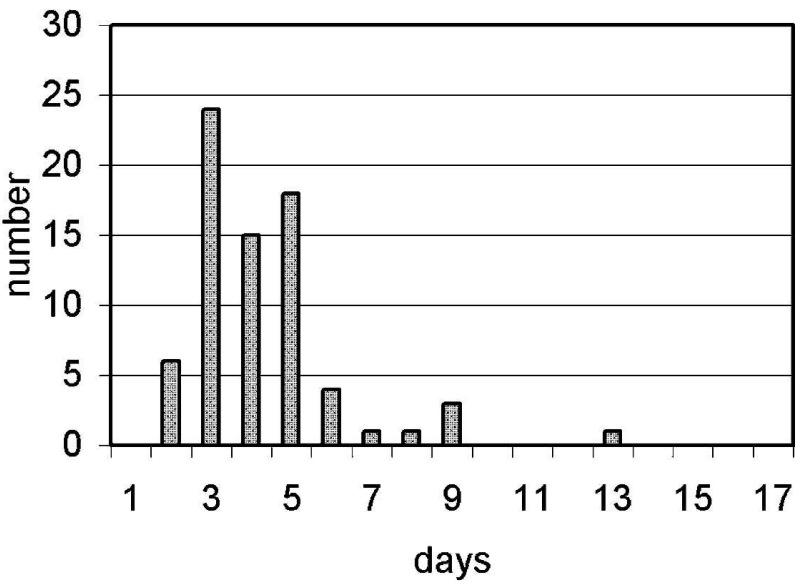

d) 1958-2002 lifetime, Sep

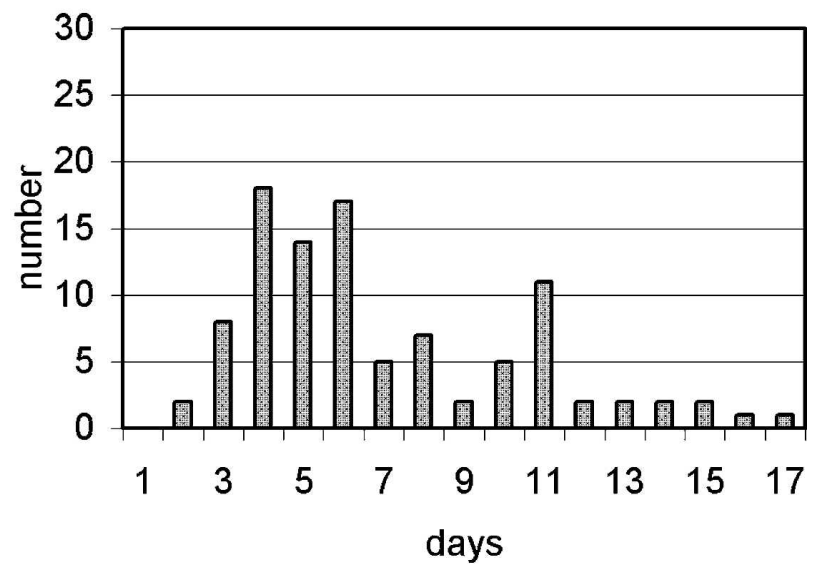

FIG. 5. Histograms of lifetime for all systems that propagate over a $10^{\circ} \times 10^{\circ}$ box centered on the genesis area of respective months [(a) June, (b) July, (c) August, (d) September, and (e) October] for all years in the dataset (1958-2002).

tember, since most intense systems originate from more intense vortices. To complete the seasonal cycle, the activity over West Africa comes to an end in October (Fig. 6e). The number of storms that intensify over the 


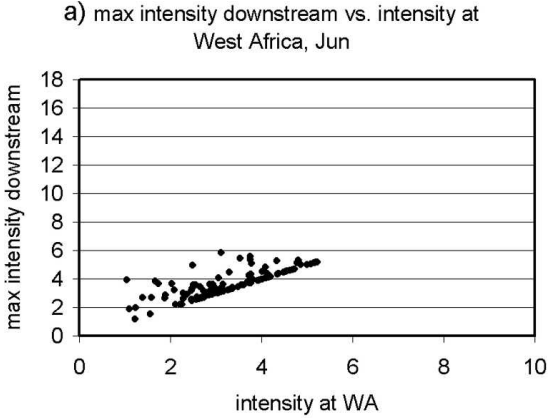

c) max intensiy downstream vs intensity at West Africa, Aug

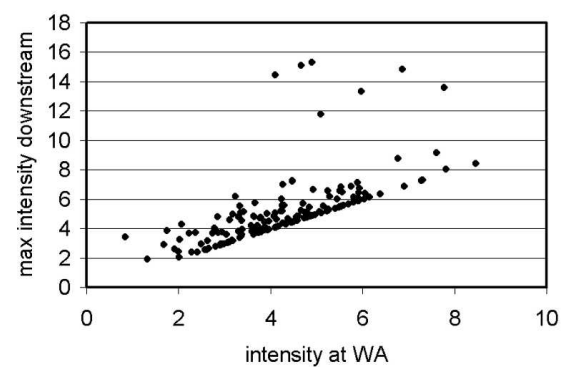

e) max intensity downstream vs intensity at West Africa, Oct

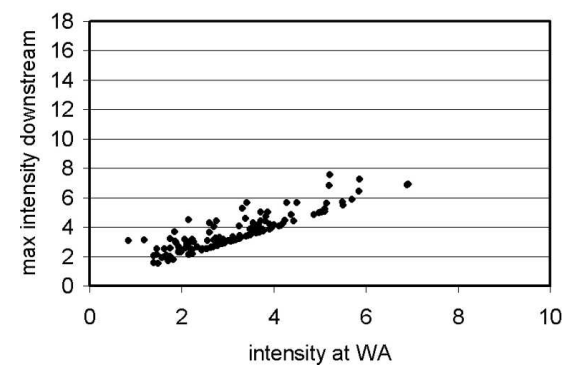

Atlantic decreases and shows strong similarity to the characteristics of the systems in June and July (Figs. $6 a, b)$.

The marked change in the lifetime of the storms during the season is likely due to a combination of the seasonal changes in the large-scale environment into which the storms move, and changes in the nature of the storms themselves (e.g., amplitude, structure, etc). Investigation of the relative roles of these two is beyond the scope of this study. It should be noted however that, in the context of this paper, there is indeed marked seasonality in the numbers of intense storms leaving the West African coast, and we would expect this to be important for tropical cyclogenesis frequency. We briefly consider this relationship below.

\section{d. Relationship with tropical cyclones}

The analysis of the storm tracks described above showed that the majority of the storms that propagate

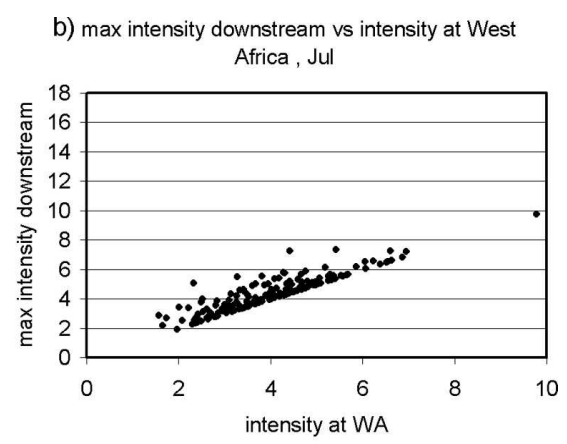

d) max intensity downstream vs intensity at West Africa, Sep

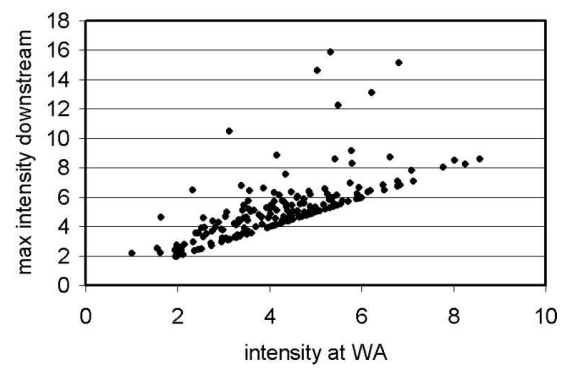

FIG. 6. Scatterplot of all individual systems' intensity $\left(10^{-5} \mathrm{~s}^{-1}\right)$ as they pass $10^{\circ}-$ $20^{\circ} \mathrm{W}$ during (a) June, (b) July, (c) August, (d) September, and (e) October vs their downstream intensity for all years in the dataset (1958-2002).

from West Africa into the tropical Atlantic originate from the southern storm track. Given that these storms are identified by their low-level vorticity signature, we might expect the numbers of these systems to impact the number of tropical cyclones initiated in the MDR. We briefly consider this here in the context of the seasonal cycle.

Figure 7 shows the seasonal cycle of the storms from the southern track (ST), all the Atlantic tropical cyclones (from NHC best-track data), and just those tropical cyclones found in the MDR (those most likely to be impacted by West African storms). Consistent with Fig. 6, there is a marked seasonal variation in the number of storms in the southern storm track with a pronounced peak in September. Interestingly, this peak in storm activity occurs in the same month as the observed peak in Atlantic tropical cyclone activity, suggesting a possible direct relationship. In contrast, the tropospheric deep vertical shear (also included in Fig. 


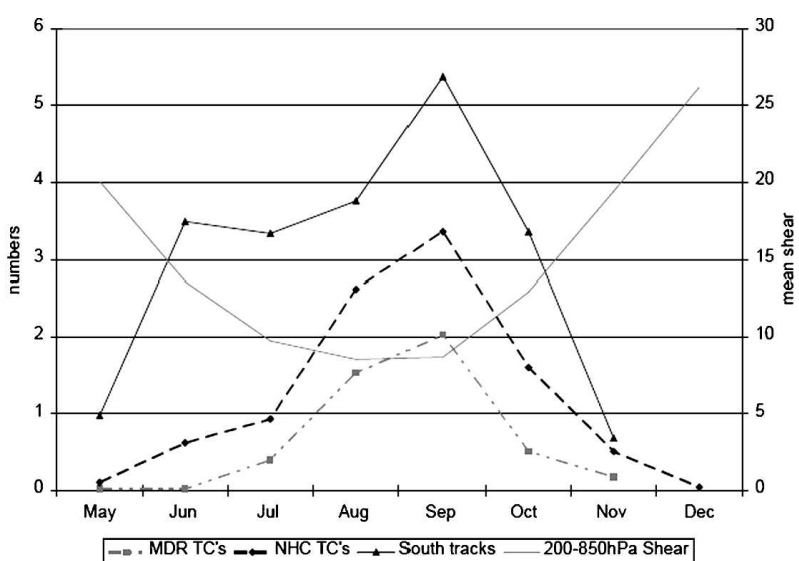

FIG. 7. Seasonal cycle for tropical cyclones (overall and MDR tropical cyclones only) and May-November tracks from the southern storm-track area from ERA-40 and for tropospheric deep wind shear (200-850 hPa, magnitude in $\mathrm{m} \mathrm{s}^{-1}$ ) over the MDR. All averages calculated using data from 1958 to 2002.

7) shows no such peak in September suggestive of the fact that seasonal variations in storm activity at the height of the tropical cyclone season may be more important than seasonal variations in the environment (measured in terms of shear). We should note though, that neither the seasonal variation in storms nor deep vertical shear exactly matches the seasonal evolution perfectly for the period considered, suggesting that a combination of these two and possibly other environmental factors, including SSTs, may be needed for a complete understanding of the seasonal cycle.

It is also worth noting in Fig. 7 that the efficiency at which storms typically become tropical cyclones in the MDR also varies during the season. It is highest in August and September when it is around $40 \%$ and much lower in June, July, and October when it is $0 \%$, roughly $12 \%$ and $15 \%$, respectively.

\section{Variability of African storm tracks}

In the previous section we highlighted the climatological characteristics of the West African storm tracks and examined how they impact the MDR. This section is concerned with the nature of the storm-track variability at interannual-to-decadal time scales. We consider the variability of the southern and northern storm tracks separately before considering how this relates to variability of tropical cyclone activity.

\section{a. Variability of the southern storm track}

Figure 8 shows the time series of the number of storms propagating in the southern storm track, which includes all systems found over a box spanning from

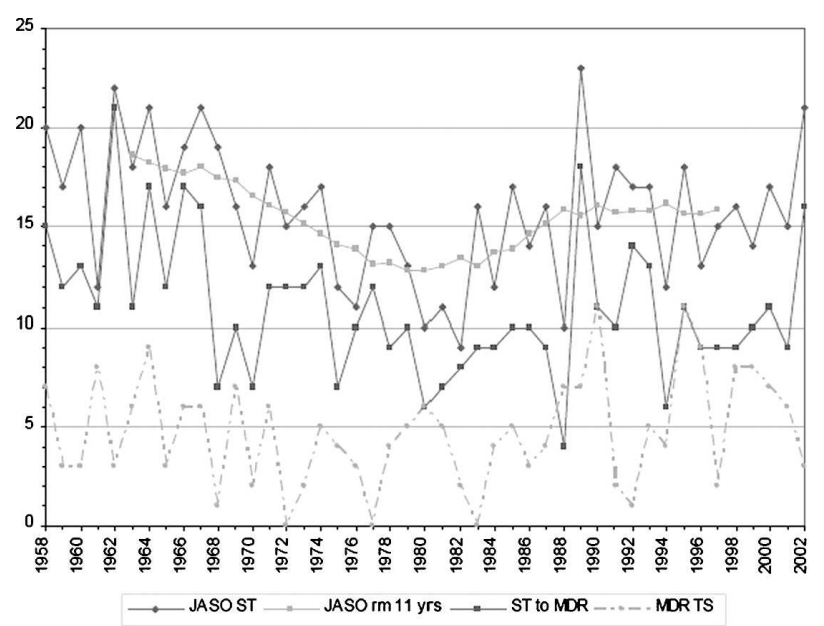

FIG. 8. Number of storms at $850 \mathrm{hPa}$ counted along the ST (thick solid) and 11-yr running mean value (RM; gray) for JulyOctober 1958-2002. Also shown is the number of storms proceeding to the MDR over the tropical Atlantic (thin solid) and the number of MDR tropical storms from the NHC best-track dataset (dash-dot-dot).

$9^{\circ}$ to $18^{\circ} \mathrm{N}$ and from $10^{\circ}$ to $20^{\circ} \mathrm{W}$, and includes all storms generated in the box as well as those passing through. The solid dark line shows the total number of storms counted during July through October within that segment, and the thin dark line shows the number that reached the MDR. For comparison, we also have included the time series of all MDR tropical storms from the NHC best-track dataset. The 45-yr average number of storms for July through October is 15.8 , and of these an average of 11 storms (i.e., $70 \%$ ) continue to the MDR. It is interesting to note that the efficiency with which the tracks reach the MDR is highly variable itself. For example, very few tracks from the southern storm track reached the MDR in 1988 (40\%), while many tracks did so in 1989 (79\%). This suggests that either the nature of the systems was different between the two years or that the large-scale environment (e.g., SSTs; cf. Fig. 13) into which these storms move also plays an important role in their life cycle. Another observation from Fig. 8 is that the number of storm tracks along the ST is always higher than the number of MDR tropical cyclones from the NHC best-track dataset and may provide an upper bound on tropical cyclone numbers of African origin. This same observation holds true for the number of ST storms that enter the MDR, with the exception of the year 1988, during which the MDR tropical cyclones tended to form farther west (see also Fig. 13 and section 4c).

The low-frequency variability in the time series in Fig. 8 is highlighted by the light solid line, which shows the 11-yr running mean. A larger number of storms 


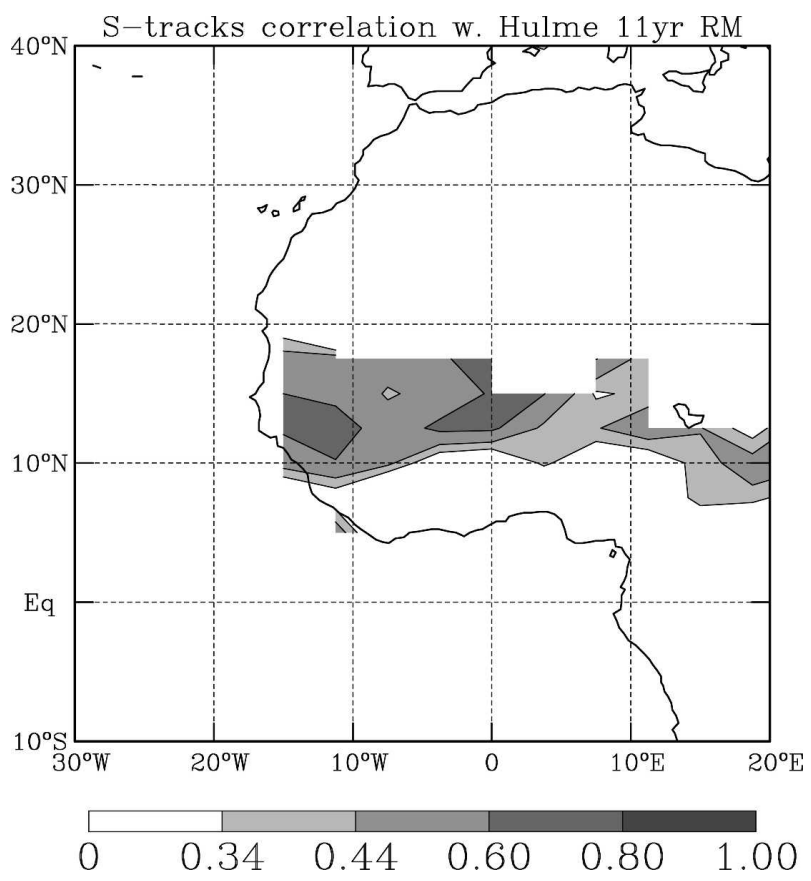

FIG. 9. Correlation map of 11-yr running mean July-October tracks from the southern storm-track area and Hulme precipitation. Shading starts at $95 \%$ significance using a Student's $t$ test.

were tracked in the 1960s compared with the 1970s and 1980s, and there is a slight indication of a recovery of higher numbers in the remainder of the time series. This low-frequency variation follows approximately the observed variability in West African rainfall, where drought conditions prevailed during much of the 1970s and 1980s (e.g., Lamb 1982; Landsea and Gray 1992; Grist and Nicholson 2001). This is also confirmed in Fig. 9, which shows a correlation map of the 11-yr running mean precipitation over West Africa with the 11yr running mean number of storms in the ST during July through October. The fact that the storm activity is well correlated with West African rainfall at these time scales is consistent with the hypothesis that the tracked storms are generated and maintained in association with moist convection. This has implications for downstream tropical cyclogenesis and is discussed in section $4 \mathrm{c}$ below.

A time series that illustrates the interannual variability of the number of storms is constructed by subtracting the low-frequency time series shown in Fig. 8 (and Fig. 11) from the raw data (see Fig. 10). The decadal and interannual variability for the southern storm track are of comparable magnitude, with standard deviations of 1.7 and 2.7, respectively. It is intriguing to note however that at interannual time scales there is no significant correlation between the number of tracked storms

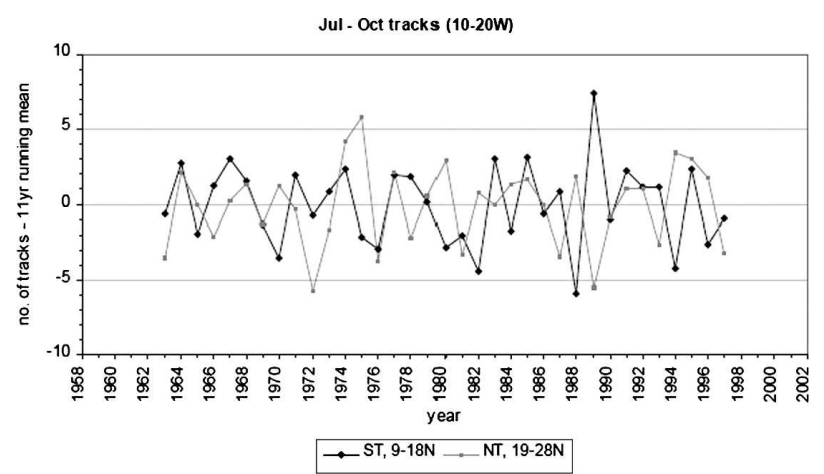

FIG. 10. Interannual variability for $850-\mathrm{hPa}$ STs and north tracks (NTs) as obtained by subtracting the 11-yr running mean value for each respective year from that year's number of counted tracks for July-October.

and West African rainfall. Given the strong positive correlation at low frequencies, this was not expected. Our results suggest therefore that during wet decades the probability of having more storms is higher than during dry decades as expected, but within these wet and dry decades the relationship between rainfall and the number of storms is more complicated. Preliminary analysis (not shown) indicates that there is substantial intraseasonal variability in the numbers of storms, such as active and inactive periods within the season and individual months, which may need to be considered in order to interpret the interannual results. It is also possible that the environmental conditions just downstream of the West African continent impact the stormtrack statistics by shortening the lifetime of the tracks below the 2-day cutoff. This will be the subject of future work.

\section{b. Variability of the northern storm track}

The time series of the number of storms in the northern storm track, which spans a box from $19^{\circ}$ to $28^{\circ} \mathrm{N}$ and from $10^{\circ}$ to $20^{\circ} \mathrm{W}$, is shown in Fig. 11. In contrast to the southern storm track, the variability of the northern track shows no apparent low-frequency variation in the time series, suggesting that this storm track is not impacted by the low-frequency rainfall variations. This may be expected since these storms are strongly linked to perturbations of the low-level baroclinic zone and do not rely on moist processes for their existence. In contrast however, there are significant variations at interannual time scales (see Fig. 10), also uncorrelated with West African rainfall. The magnitude of the interannual variations in the northern and southern storm tracks is very similar, but these variations are not significantly correlated with each other. 

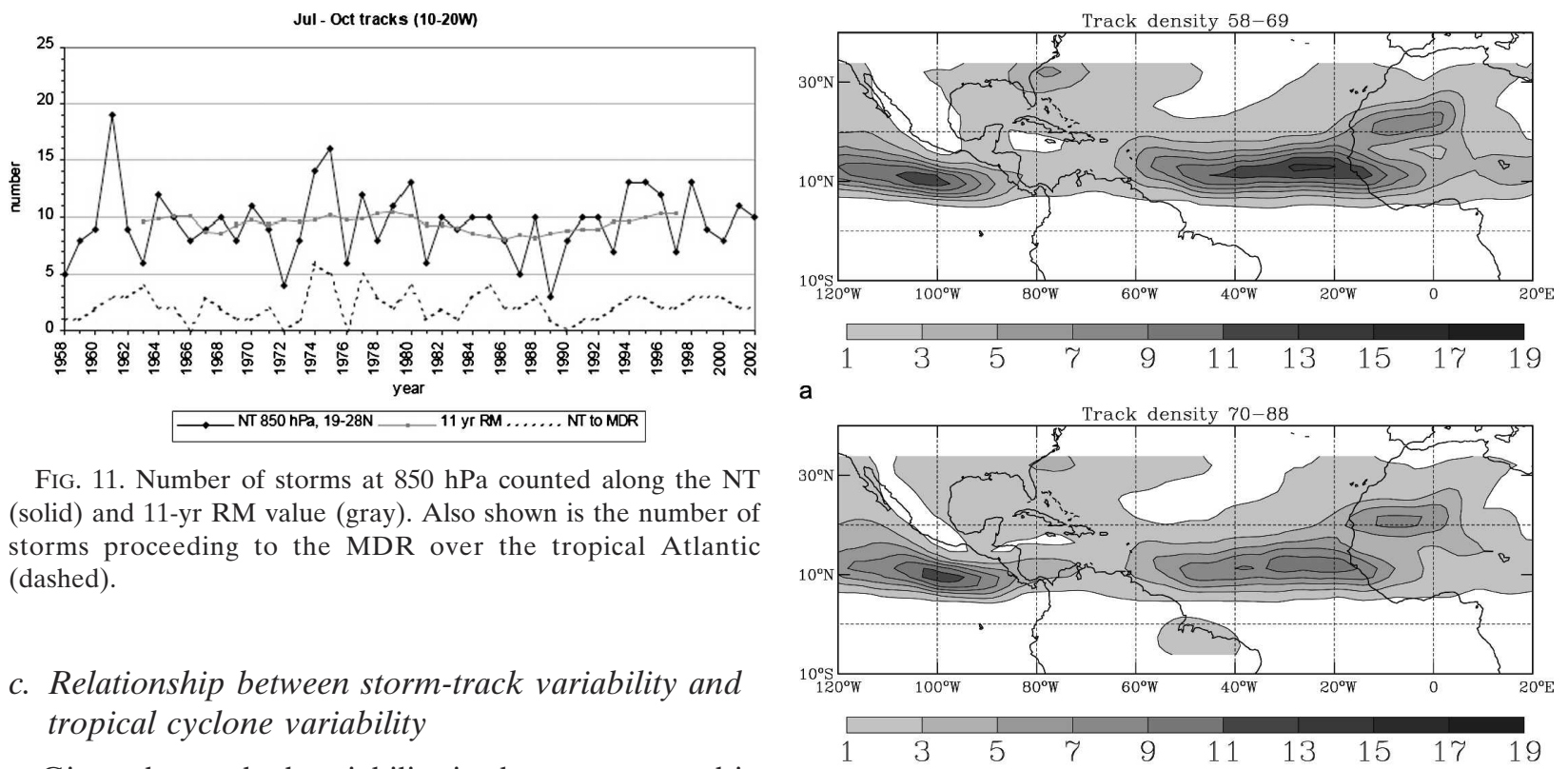

\section{c. Relationship between storm-track variability and tropical cyclone variability}

Given the marked variability in the storms noted in the previous section, we now briefly consider whether this may have impacted the variability of tropical cyclones forming downstream. For simplicity we consider variability at decadal and interannual time scales separately.

The only low-frequency storm variability over West Africa of any note was seen in the southern storm track. As a first step to see if this related to similar variability downstream we show the geographical storm-track density for the active and inactive periods highlighted in Fig. 8. Figure 12 shows "unfiltered" track density maps for the active periods of 1958-69 and 1989-2002, as well as the relatively inactive period of 1970-88. The figure clearly shows that the anomalous storm activity in the southern storm track over West Africa varies consistently with the storm activity over the tropical Atlantic, showing that 1970-88 experiences lower track densities than the other two periods in concert with the low-frequency variability of storms leaving West Africa, as shown in Fig. 8. ${ }^{2}$

The fact that the storm activity leaving the West African coast appears to vary in concert with the storm activity (and tropical cyclone activity) over the tropical Atlantic suggests that the tropical cyclone precursors emanating from the southern storm track may contribute a nonlocal effect to the multidecadal signal of tropi-

\footnotetext{
${ }^{2}$ Given that caution is needed when using the reanalysis data for the presatellite era (i.e., 1958-78) we compared the stormtrack densities for the $1979-88$ period and the $1970-88$ periods (not shown). There was little significant difference, giving us some confidence at least in the differences between the inactive and following active period.
}

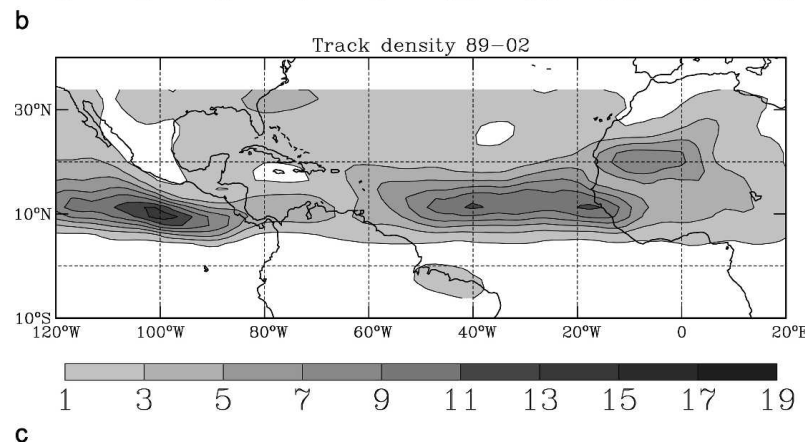

FIG. 12. Mean track density \{scaled to number density per unit area [with unit area equivalent to a $5^{\circ}$ radius spherical cap $\left(\sim 10^{6}\right.$ $\mathrm{km}^{2}$ )] per season (JASO)\} for (a) the active period from 1958 to 1969, (b) the inactive period from 1970 to 1988, and (c) the active period from 1989 to 2002.

cal cyclone activity. An alternative interpretation is that the storm activity over West Africa and tropical cyclone activity over the tropical Atlantic are both impacted by the same slowly evolving sea surface temperature patterns often referred to as the Atlantic Multidecadal Oscillation (AMO; e.g., Mestas-Nuñez and Enfield 1999; Goldenberg et al. 2001).

While the southern storm track also exhibited significant interannual variability, we found that this is not significantly correlated with Atlantic tropical cyclone activity. This disagrees with the suggestion made by TH01, that tropical cyclones may be weakly but positively correlated with the numbers of storms. In fact, even the short period in TH01 where there appeared to be a positive correlation (1985-98) is not reproduced in the present analysis. The reasons for the differences are not easy to determine, although it should be noted that 


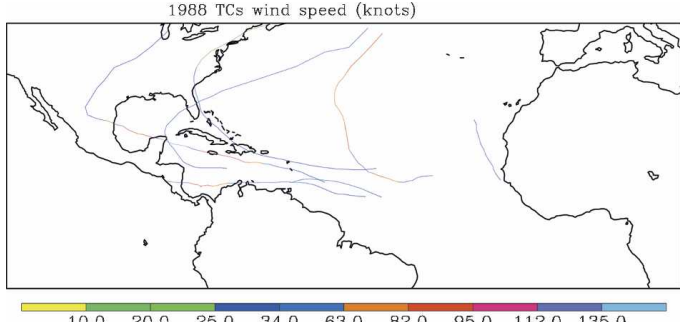

a)

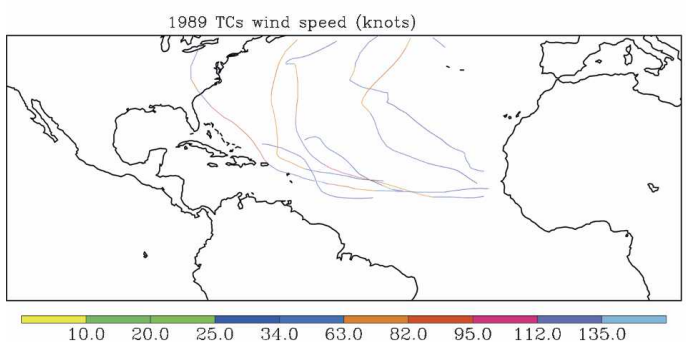

c)

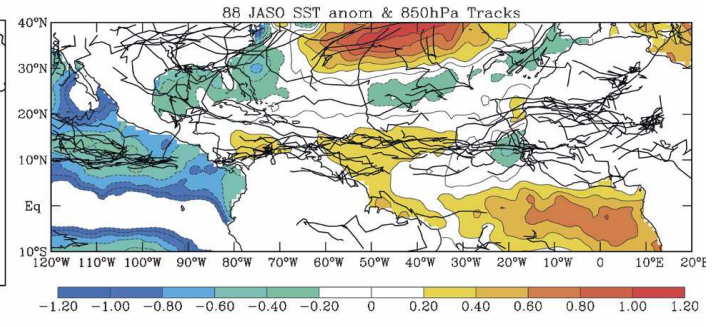

b)

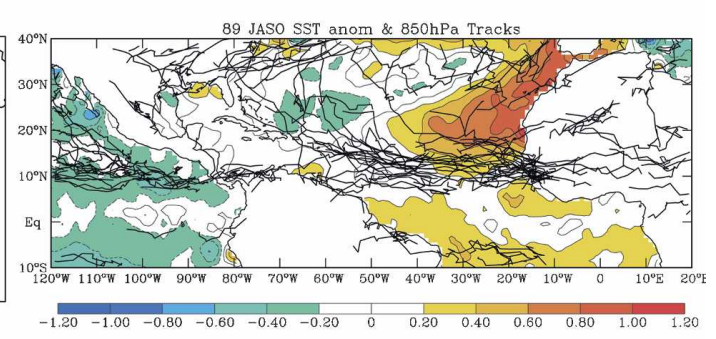

d)

FIG. 13. (a) Tropical storm tracks from NHC best-track data for MDR storms (wind speed in kt), formed in 1988. (b) Storm tracks (solid black) for July-October 1988 from ERA-40 overlaid on SST anomalies (contours every $0.2^{\circ} \mathrm{C}$, positive anomalies in warm colors, negative anomalies in cold colors). (c) Same as in (a), but for 1989, and (d) same as in (b), but for 1989.

TH01 used arguably a reanalysis product (ERA-15) that is not as good as the one used in the current study, together with operational analysis that included years where different assimilation systems were used and the resolution progressively increased. The best correlation with tropical cyclones in the TH01 study appeared to be exactly when the operational analyses were used. This highlights the need for further reanalyses with higher resolutions and better data assimilation such as fourdimensional variational data assimilation (4DVAR).

In the absence of a higher-resolution reanalysis dataset we argue that the present analysis provides us with our most objective view of the variability of the storms. However, we recognize the need to continue to assess these results with future improved reanalysis datasets.

\section{Discussion}

The study has shown that there exists considerable year-to-year variability in the number of West African storm tracks, both in numbers over the land and continuing out over the tropical Atlantic Ocean. While the low-frequency variability is well correlated with Atlantic tropical cyclones, West African rainfall, and SSTs (not shown), the interannual variability is not as easily explained. Toward helping us interpret this result we briefly consider two extreme years in the time series,
1988 and 1989 (cf. Fig. 8). These two years contained the least active and most active seasons in the stormtrack data.

Figure 13 shows maps of all named tropical storms from the NHC best-track data (Figs. 13a,c) and maps of all storm tracks found in ERA-40 overlaid on JulyOctober SST anomalies (Figs. 13b,d) for the two contrasting years, 1988 and 1989. Figure 13b shows the ERA-40 tracks for 1988. Note that relatively few coherent storms are found over the southern storm-track area (10 compared with 23 in 1989-see Fig. 8), and that more storms appear to be generated farther west over the tropical Atlantic. In contrast, Fig. 13d shows the ERA-40 tracks for 1989 and confirms that many storms are generated over the Guinea Highlands and the adjacent tropical Atlantic. While seven named Atlantic tropical storms formed within the MDR in both years, the genesis location differed markedly. Namely, the tropical storms were formed farther west during 1988 (Fig. 13a), whereas they formed directly offshore of West Africa in 1989 (Fig. 13c). In both years the Atlantic tropical storms formed during months in which the ST was most active, and we were able to identify all official tropical storms in the dataset (figures not shown). It appears that the environmental influences, shown here by the SST anomaly maps, may have played an important role in aiding/hindering formation and/or propagation of the storms in the ST. Closer inspection 


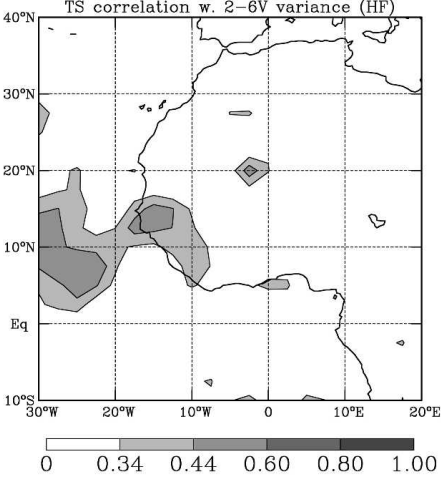

a

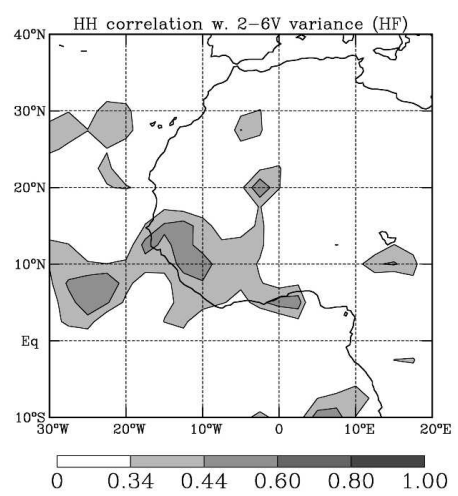

b

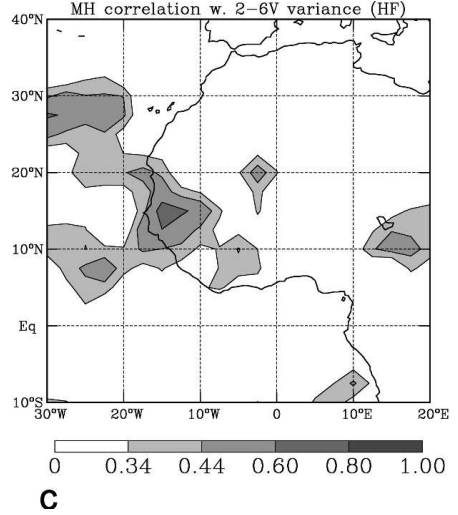

FIG. 14. (a) Interannual correlation of tropical storms in the MDR (from best-track data) and 2-6-day-filtered meridional wind variance from the 850-hPa level for July-October for 1963 to 1996 from ERA-40. Contouring starts at the 95\% significance level using a Student's $t$ test. (b) Same as in (a), but correlation with MDR hurricanes; and (c) same as in (a), but for MDR major hurricanes.

of individual tropical cyclogenesis events (not shown) indicates that five out of the seven tropical cyclones that formed in the MDR in 1988 were related to synoptic-scale AEWs (figures not shown) originating over the continent but are not associated with coherent vorticity structures originating there. In contrast to 1989 , though, was the absence of storms emanating from the southern storm track. This is a reminder of the need to consider the variability of a synoptic measure of AEW activity, as discussed in the introduction.

For completeness, therefore we computed the 2-6day-filtered meridional wind variance on the $850-\mathrm{hPa}$ level from the ERA-40 daily data to compare this with the storm-track measure as well as with tropical cyclone activity. The seasonal cycle of this synoptic measure (not shown) indicates an increase in activity between May and July, very little change after that during August and September, and then a decrease in activity after September. It does not have the marked September peak that the storm tracks clearly have (see Fig. 7). This serves to show us that the two different measures of AEW activity are not necessarily related. It is very likely that synoptic-scale AEWs can exist in the absence of coherent convectively generated structures, and the reverse may equally be true; namely that coherent structures can exist in the absence of a strong AEW. A more detailed analysis of individual events is needed to shed more light on this issue (see, e.g., Berry et al. 2007).

In addition to mean seasonal variations, our analysis indicates that there is also no significant correlation between synoptic AEW activity and the storm tracks at interannual-to-decadal time scales (not shown). Interestingly though, while the storm-track measure has no significant correlation with tropical cyclone activity at interannual time scales, the synoptic measure does. Figure 14a shows maps of the interannual correlation of the filtered wind variance with tropical storms in the MDR, with MDR hurricanes (Fig. 14b), and with MDR major hurricanes (Fig. 14c). While the subsynopticscale structures over West Africa correlated poorly with the Atlantic tropical cyclone activity the figure shows that the synoptic-scale AEWs are well correlated with Atlantic tropical cyclones at this time scale. It is interesting to see that the interannual correlation with the Guinea Highlands is particularly enhanced for major hurricanes. This further stresses the importance of this geographic area for tropical Atlantic and West African weather systems, as was also seen in the climatological track genesis density (Fig. 2b).

These results provide us with an intriguing situation regarding the relationship between AEWs and Atlantic tropical cyclone activity. On the one hand, the coherent structures exhibit a peak in the mean seasonal cycle that matches that of the MDR tropical cyclones and have exhibited low-frequency variations that also match those of the tropical cyclones. On the other hand, at interannual time scales, while variability of the coherent structures does not correlate significantly with tropical cyclone activity, variability of the synoptic measure of AEW activity does.

We suggest that the simplest interpretation is the following. The low-frequency variability is consistent with low-frequency tropical cyclone variability. The coherent structures develop in association with convection, which in turn is sensitive to the slowly varying SST patterns. This variation is approximately in concert with the AMO. While one phase encourages convection in the east Atlantic including West Africa, the opposite phase suppresses convection there. On interan- 
nual time scales the situation is more complicated-as shown by the 1988/89 example. Synoptic AEWs can propagate across the Atlantic and be responsible for the development of tropical cyclones far from West Africa. We suggest that these are more "robust" features than the subsynoptic-scale storms and can have long lifetimes with or without convection embedded, as discussed in the beginning of this section. Other largescale influences may well become important for the development and fate of these systems within active or inactive epochs, too.

\section{Summary and final comments}

In this paper we have used relative vorticity tracks from ECMWF's ERA-40 dataset over West Africa and the tropical North Atlantic on the 850-hPa level to generate a climatology and seasonal cycle of activity and examined the nature and variability of these tracks at interannual-to-decadal time scales.

The seasonal mean confirmed the existence of two main storm tracks over the land, one to the north on the fringes of the Sahara, and the other to the south in the rainy zone. The latter is much more dominant and extends far out over the tropical Atlantic Ocean, along a path often preferred by Atlantic tropical cyclones. We have also shown that most storm tracks that can be found inside the MDR are propagating along the southern storm track, and that the Guinea Highlands area is the main genesis region for these storm tracks. Systems from the northern storm track are rarely found to enter the MDR and usually dissipate very shortly after they leave the West African coast. The overall pattern and characteristics also revealed the presence of a marked seasonal cycle, with a prominent peak in activity in September. The geographical location of both track and genesis densities shows that both the northern and southern storm tracks are active during the early months of the season (June and July). As the season progresses from August to September the southern storm track becomes much more important and becomes the main source region for the tracks that propagate into the MDR. The average intensity and longevity of the storms reach their maximum values during the most active period in August and September, thereby providing better precursors for possible downstream tropical cyclogenesis. The relative roles of the environmental conditions in the tropical Atlantic and the storm characteristics leaving the West African coast on the peak intensity downstream, as well as their longevity, still needs clarification. Future work will address this point in more detail. Note also that both the Atlantic tropical cyclone activity and number of tracked storms along the southern storm track exhibit a very similar peak activity in the seasonal cycle, and that there always were more tracked storm centers (possible precursors) available than the number of named tropical cyclones for each year, suggesting that this may provide an upper bound on tropical cyclone numbers of African origin.

There exists considerable year-to-year variability in the number of West African storm tracks, both in numbers over the land and continuing out over the tropical Atlantic Ocean. While the low-frequency variability is well correlated with Atlantic tropical cyclones, West African rainfall, and SSTs, the interannual variability is found to be uncorrelated. In contrast, however, a significant positive correlation was found between the 2-6-day-filtered meridional wind and Atlantic tropical cyclone activity. The signal was particularly strong for the Guinea Highland area, which is the most dominant genesis region for the analyzed storm tracks that propagate off the West African coast. This highlights the need for better and more observations in that region in order to better understand the nature and variability of the storm tracks that propagate or originate in that area, and to be able to address the interaction of subsynoptic- and synoptic-scale features. We should note again however that the confidence in the results on the interdecadal variability of the storm tracks is restricted by the lack of satellite data in the early period of the reanalysis, although the change from inactive to active periods is indeed captured within the satellite period. In future work, we will examine how the storm tracks relate to the synoptic scale in more detail. Additionally, the vertical structure and its variation over the lifetime and season will be examined, including closer inspection of ocean genesis versus land-based genesis of storms.

Acknowledgments. We want to thank three anonymous reviewers whose comments greatly helped to improve this manuscript. ERA-40 data were provided by the ECMWF from their Web site (http://data.ecmwf. int/data/d/era40_daily/). This research was supported by the National Sciene Foundation under Grant ATM0138290.

\section{REFERENCES}

Aiyyer, A., and C. Thorncroft, 2006: Climatology of vertical shear over the tropical Atlantic. J. Climate, 19, 2969-2983.

Avila, L., and R. J. Pasch, 1992: Atlantic tropical systems of 1991. Mon. Wea. Rev., 120, 2688-2696.

Berry, G., and C. Thorncroft, 2005: Case study of an intense African easterly wave. Mon. Wea. Rev., 133, 752-766.

,$- \ldots$, and T. Hewson, 2007: African easterly waves during 2004-Analysis using objective techniques. Mon. Wea. Rev., 135, 1251-1267. 
Burpee, R. W., 1972: The origin and structure of easterly waves in the lower troposphere of North Africa. J. Atmos. Sci., 29, 77-90.

Charney, J. G., and M. E. Stern, 1962: On the stability of internal baroclinic jets in a rotating atmosphere. J. Atmos. Sci., 19, 159-172.

Diedhiou, A., S. Janicot, A. Viltard, P. de Felice, and H. Laurent, 1999: Easterly wave regimes and associated convection over West Africa and the tropical Atlantic: Results from NCEP/ NCAR and ECMWF reanalyses. Climate Dyn., 15, 795-822.

Emanuel, K., 2003: Tropical cyclones. Annu. Rev. Earth Planet. Sci., 31, 75-104.

Frank, N. L., 1975: Atlantic tropical systems of 1974. Mon. Wea. Rev., 103, 294-300.

Gibson, J. K., P. Kållberg, S. Uppala, A. Hernandez, A. Nomura, and S. Serrano, 1997: ECMWF Reanalysis Project. Rep. Series $1,71 \mathrm{pp}$.

Goldenberg, S., and L. Shapiro, 1996: Physical mechanisms for the association of El Niño and West African rainfall with Atlantic major hurricane activity. J. Climate, 9, 1169-1187.

_ C. W. Landsea, A. M. Mestas-Nuñez, and W. M. Gray, 2001: The recent increase in Atlantic hurricane activity: Causes and implications. Science, 293, 474-479.

Gray, W. M., 1968: Global view of the origins of tropical cyclones. Mon. Wea. Rev., 96, 669-700.

Grist, J. P., and S. E. Nicholson, 2001: A study of the dynamic factors influencing the rainfall variability in the West African Sahel. J. Climate, 14, 1337-1359.

Hodges, K., 1995: Feature tracking on the unit sphere. Mon. Wea. Rev., 123, 3458-3465.

_ 1996: Spherical nonparametric estimators applied to the UGAMP model integration for AMIP. Mon. Wea. Rev., 124, 2914-2932.

Hulme, M., 1992: A 1951-80 global land precipitation climatology for the evaluation of General Circulation Models. Climate Dyn., 7, 57-72.

Kiladis, G., C. Thorncroft, and N. Hall, 2006: Three-dimensional structure and dynamics of African easterly waves. Part I: Observations. J. Atmos. Sci., 63, 2212-2230.

Lamb, P. J., 1982: Persistence of Subsaharan drought. Nature, 299, 46-48.

Landsea, C., and W. Gray, 1992: The strong association between western Sahelian monsoon rainfall and intense Atlantic hurricanes. J. Climate, 5, 435-453.

— - G. D. Bell, W. Gray, and S. B. Goldenberg, 1998: The extremely active 1995 Atlantic hurricane season: Environmental conditions and verification of seasonal forecasts. Mon. Wea. Rev., 126, 1174-1193.

Lau, K.-H., and N.-C. Lau, 1990: Observed structure and propagation characteristics of tropical summertime synoptic-scale disturbances. Mon. Wea. Rev., 118, 1888-1913.
Mekonnen, A., C. Thorncroft, and A. Aiyyer, 2006: Analysis of convection and its association with African easterly waves. $J$. Climate, 19, 5405-5421.

Mestas-Nuñez, A. M., and D. B. Enfield, 1999: Rotated global modes of non-ENSO sea surface temperature variability. $J$. Climate, 12, 2734-2746.

Pasch, R. J., and L. Avila, 1994: Atlantic tropical systems of 1992 Mon. Wea. Rev., 122, 539-548.

Rayner, N. A., D. E. Parker, E. B. Horton, C. K. Folland, L. V. Alexander, D. P. Rowell, E. C. Kent, and A. Kaplan, 2003: Global analyses of SST, sea ice, and night marine air temperature since the late nineteenth century. J. Geophys. Res., 108, 4407, doi:10.1029/2002JD002670.

Reed, R. J., 1988: On understanding the meteorological causes of Sahelian drought. Persistent Meteo-Oceanographic Anomalies and Teleconnections, C. Chagas and G. Puppi, Eds., Pontificae Academiae Scientiarvm, 179-213.

_ D. C. Norquist, and E. E. Recker, 1977: The structure and properties of African wave disturbances as observed during Phase III of GATE. Mon. Wea. Rev., 105, 317-333.

—, A. Hollingsworth, W. A. Heckley, and F. Delsol, 1988: An evaluation of the performance of the ECMWF operational system in analyzing and forecasting easterly wave disturbances over Africa and the tropical Atlantic. Mon. Wea. Rev., 116, 824-865.

Schubert, W. H., P. E. Ciesielski, D. E. Stevens, and H.-C. Kuo, 1991: Potential vorticity modeling of the ITCZ and the Hadley circulation. J. Atmos. Sci., 48, 1493-1500.

Simpson, R. H., N. Frank, D. Shideler, and H. M. Johnson, 1969: Atlantic tropical disturbances of 1968. Mon. Wea. Rev., 97, 240-255.

Thorncroft, C., and B. J. Hoskins, 1994a: An idealized study of African Easterly Waves, part I: A linear view. Quart. J. Roy. Meteor. Soc., 120, 953-982.

_ , and — 1994b: An idealized study of African Easterly Waves, part II: A nonlinear view. Quart. J. Roy. Meteor. Soc., 120, 983-1015.

_ , and K. Hodges, 2001: African easterly wave variability and its relationship to Atlantic tropical cyclone activity. J. Climate, 14, 1166-1179.

_ , and I. Pytharoulis, 2001: A dynamical approach to seasonal prediction of Atlantic tropical cyclone activity. Wea. Forecasting, 16, 725-734.

- and Coauthors, 2003: The JET2000 Project: Aircraft observations of the African easterly jet and African easterly waves. Bull. Amer. Meteor. Soc., 84, 337-351.

Uppala, S. M., and Coauthors, 2005: The ERA-40 re-analysis. Quart. J. Roy. Meteor. Soc., 131, 2961-3012.

Webster, P., and H.-R. Chang, 1988: Equatorial energy accumulation and emanation regions: Impacts of a zonally varying basic state. J. Atmos. Sci., 45, 803-829. 